\title{
17-jähriger Schüler mit Halslymphknotenschwellungen
}

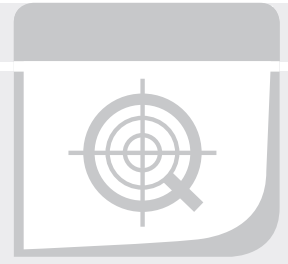

\section{7-Year-Old Pupil with Cervical Lymphe Node Masses}

\section{Autoren}

Klaus Muehlenberg, Anna Philine Karl, Oliver Pech

Institut

Klinik für Gastroenterologie und interventionelle Endoskopie,

Krankenhaus Barmherzige Brüder, Regensburg
Bibliografie

DOI https://doi.org/10.1055/a-0696-0251

Dtsch Med Wochenschr 2018; 143: 1671-1672

(c) Georg Thieme Verlag KG, Stuttgart · New York

ISSN 0012-0472

\section{Korrespondenzadresse}

Dr. med. Klaus Muehlenberg

Klinik für Gastroenterologie und interventionelle Endoskopie Krankenhaus Barmherzige Brüder, Prüfeninger Str. 86, 93049 Regensburg

klaus.muehlenberg@barmherzige-regensburg.de

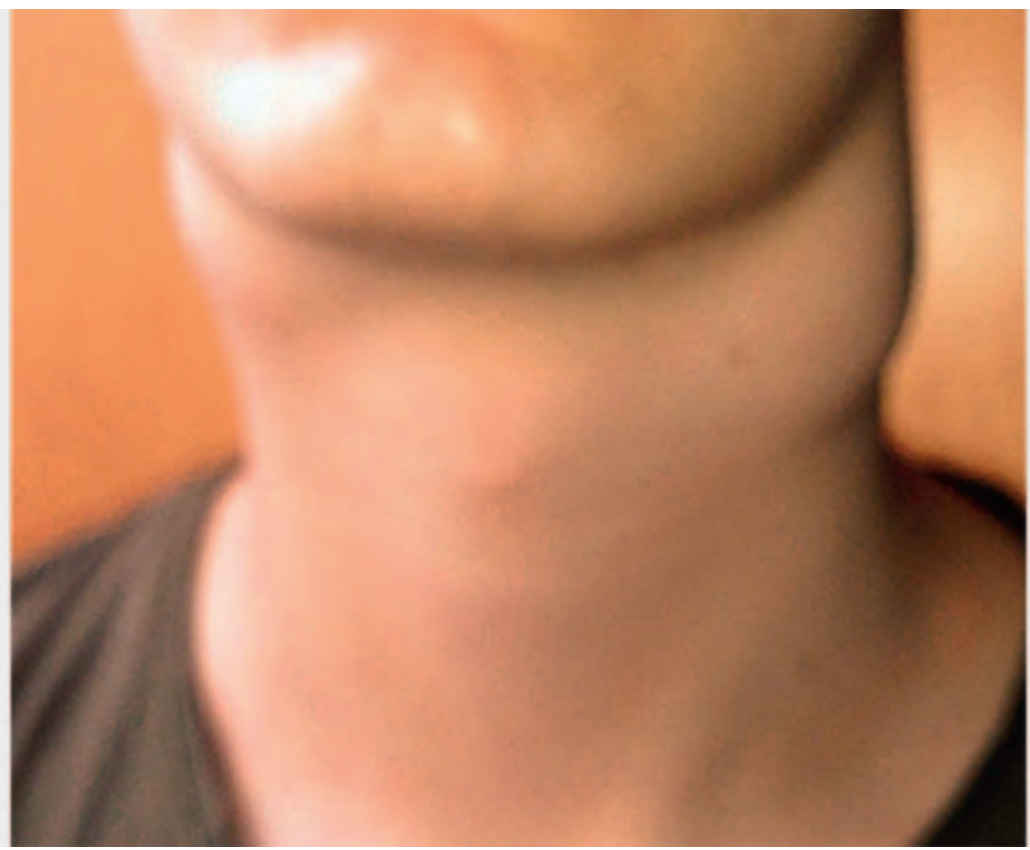

- Abb. 1 Beidseitige Halslymphknotenschwellungen.

Der 17-jährige Schüler erkrankte im Sommer mit Fieber, Halsschmerzen und zervikalen Lymphknotenschwellungen. Nach Therapie mit einem Breitbandantibiotikum besserten sich die Beschwerden nicht. Klinisch und sonografisch wurden einschmelzende Hals-Lymphknoten bis $3 \mathrm{~cm}$ vorgefunden. Umfangreiche Labortests blieben zunächst ergebnislos. Die Abbildung weist einen pathologischen Befund auf.

\section{FRAGEN}

- Welcher Befund ist es?

- Erlaubt dieser Befund eine Diagnose? Wenn ja, welche?

- Sind Differenzialdiagnosen möglich? Wenn ja, welche? 


\section{7-jähriger Schüler mit Halslymphknotenschwellungen}

\section{7-Year-Old Pupil with Cervical Lymphe Node Masses}

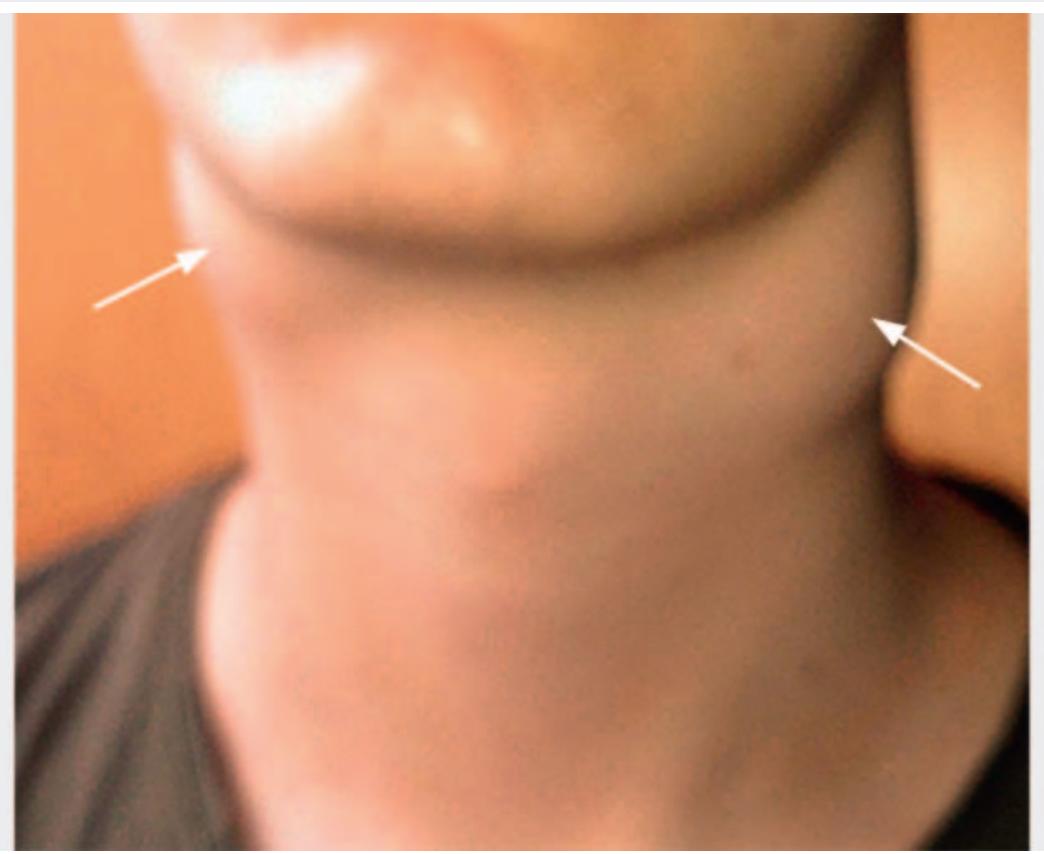

- Abb. 2 Beidseitige Halslymphknotenschwellungen.

\section{Befunde}

Zervikale Lymphadenopathie

\section{Differenzialdiagnosen}

Die Abbildung und klinische Symptomatik lassen keine Diagnose zu. Sie führen zu folgenden Differenzialdiagnosen, insbesondere

- Pfeiffersches Drüsenfieber

- Lymphom

- Tuberkulose

- Bartonellose

- Toxoplasmose

\section{Erläuterung}

Umfangreiche Labortests blieben zunächst ergebnislos, insbesondere Untersuchungen auf Epstein-Barr und HI-Virus. Gewebeproben wiesen eine einschmelzende nekrotisierende Entzündung auf, ohne Hinweise auf die wichtigsten Differenzialdiagnosen Lymphom und Tuberkulose. Die Suche nach der infektiösen Ursache ergab schließlich positive Befunde auf Francisella tularensis (PCR im Biopsat und Serologie) so dass die Diagnose einer Tularämie (Hasenpest) gestellt wurde.
Die Tularämie (Hasenpest) ist eine seltene, häufig durch kleine säugende Wildtiere übertragene bakterielle Infektion mit unspezifischer Symptomatik, Fieber und Lymphadenopathie [1, 2]. Wir vermuten, dass unser Patient durch einen Vektor (Mücke, Bremse, Zecke) oder infizierte Flüssigkeit infiziert wurde, da ein direkter Tierkontakt nicht eruierbar war. Vor kurzem wurde über die Häufung einer oropharyngealen Tularämie berichtet, die durch den Verzehr von frisch gepresstem Traubenmost durch Erntehelfer in Rheinland-Pfalz entstand [3]. Diese Formen der Übertragung können Grund einer erheblichen Dunkelziffer sein. Daher ist bei unklarem fieberhaftem Krankheitsbild auch ohne typische Anamnese eine Tularämie differenzialdiagnostisch zu erwägen. Ciprofloxacin oral über 3 Wochen führte bei unserem Schüler zur Ausheilung.

\section{Literatur}

[1] Maurin M, Gyuranecz M. Tularaemia: clinical aspects in Europe. Lancet Infect Dis 2016; 16: 113-124

[2] Faber M, Heuner K, Jacob D et al. Tularemia in Germany-A Re-emerging Zoonosis. Front Cell Infect Microbiol 2018; 8: 40

[3] Burckhardt F, Hoffmann D, Jahn K et al. Oropharyngeal Tularemia from Freshly Pressed Grape Must. N Engl J Med 2018; 379: 197-199 